\title{
Tentative chromosomal assignment of the glucose phosphate isomerase gene in cattle, sheep and goat by in situ hybridization
}

\author{
BP Chowdhary ${ }^{1}$, I Harbitz², W Davies², I Gustavsson ${ }^{1}$ \\ 1 Swedish University of Agricultural Sciences, \\ Department of Animal Breeding and Genetics, Uppsala, Sweden; \\ ${ }^{2}$ Norwegian College of Veterinary Medicine, Department of Biochemistry, Oslo, Norway \\ (Proceedings of the 9th European Colloquium on Cytogenetics of Domestic Animals; \\ Toulouse-Auzeville, 10-13 July 1990)
}

gene mapping / in situ hybridization / glucose phosphate isomerase (GPI) / cattle, sheep and goat

\section{INTRODUCTION}

Cattle, sheep and goat are evolutionarily closely related species belonging to the family Bovidae. Karyologically, on the basis of GTG- and RBA-bands, the three species are quite similar except for the sex chromosomes and minor differences between some autosomes (ISCNDA, 1989). Much data have accumulated in the past decade which suggest that, in the majority of the cases, chromosome-banding homologies correspond to similarities in the gene content. This conclusion is based on the results of the comparative banding and gene mapping studies carried out in human, big apes and New World monkeys (Dutrillaux et al, 1981; Lalley et al, 1989), along with comparisons made between man and mouse (Sawyer and Hozier, 1986), within the group of Cricetidae and Muridae (Yoshida, 1984; Levan et al, 1987), between cat and human (O'Brien et al, 1985), and cat and mink (Graphodatsky, 1989). In phylogenetically distant species, however, comparative banding and gene mapping homologies are less evident. In domestic animals, very few studies involving such comparisons have yet been made. The assignment of the major histocompatibility complex (MHC), cytokeratin A (KRTA) and cytokeratin B (KRTB) genes in cattle and sheep (Hediger, 1988; Mahdy et al, 1989) support the similar banding-similar gene concept.

\section{MATERIALS AND METHODS}

A porcine genomic glucose phosphate isomerase (GPI) DNA (GPI8R) was used for in situ hybridization in cattle, sheep and goat. Hybridization of GPI8R and a GPI 
cDNA to genomic blots from the same species indicated that the porcine genomic probe binds to the GPI locus in these species (results not shown). The probe was tritium labeled using the random-priming method (Feinberg and Vogelstein, 1983; Lin et al, 1985). The specific activity of the probe was $5 \times 10^{8} \mathrm{dpm} / \mu \mathrm{g}$ of DNA. Lymphocytes from two Swedish Red and White bulls, two Swedish Landrace ewes and two Finnish Landrace bucks were cultured using standard techniques. The chromosome preparation method and the technique of in situ hybridization have been described elsewhere (Mäkinen et al, 1989). The chromosomes were GTGbanded after hybridization using the technique described by Popescu et al (1985). The idiograms of G-banded chromosomes of cattle were adapted for sheep and goat chromosomes and the grains were plotted on these idiograms (ISCNDA, 1989). The $\chi^{2}$-test was used for statistical analysis.

\section{RESULTS}

\section{Cattle}

A total of 113 metaphases from two experiments were analyzed and the grains scored were plotted on the idiogram of G-banded cattle chromosomes (fig 1a). In all, 363 grains were counted, of which $80(22 \%)$ were located on chromosome 18 . Furthermore, of the total number of grains on this chromosome, 75 (94\%) were located on the distal half of the chromosome with the peak on segment $\mathrm{q} 22 \rightarrow$ proximal part of q24, where approximately $73 \%$ (58) of the total number of grains on chromosome 18 were located.

\section{Sheep}

A total of 118 metaphases from two experiments were analyzed and the grains scored were plotted on the idiogram of G-banded sheep chromosomes (fig 1b). In all, 495 grains were counted, of which 93 (19\%) were located on chromosome 14. Furthermore, of the total number of grains on this chromosome, $81(87 \%)$ were located on the distal half of the chromosome with the peak on the segment $\mathrm{q} 22 \rightarrow$ proximal part of $\mathrm{q} 24$, where approximately $62 \%$ (58) of the total grains on chromosome 14 were located.

\section{Goat}

A total of 121 metaphases from two experiments were analyzed and the grains scored were plotted on the idiogram of G-banded goat chromosomes (fig 1c). The sex chromosomes were drawn on the basis of the photographs of G-banded X and Y chromosomes. In all, 479 grains were counted, of which 61 (13\%) were located on chromosome 18. Of the total number of grains on this chromosome, about $56(92 \%)$ were localized on the distal half of the chromosome. A close examination revealed that the peak clustered in the q22 $\rightarrow$ proximal part of q24 with about $69 \%$ (42) of the total grains on chromosome 18 . 


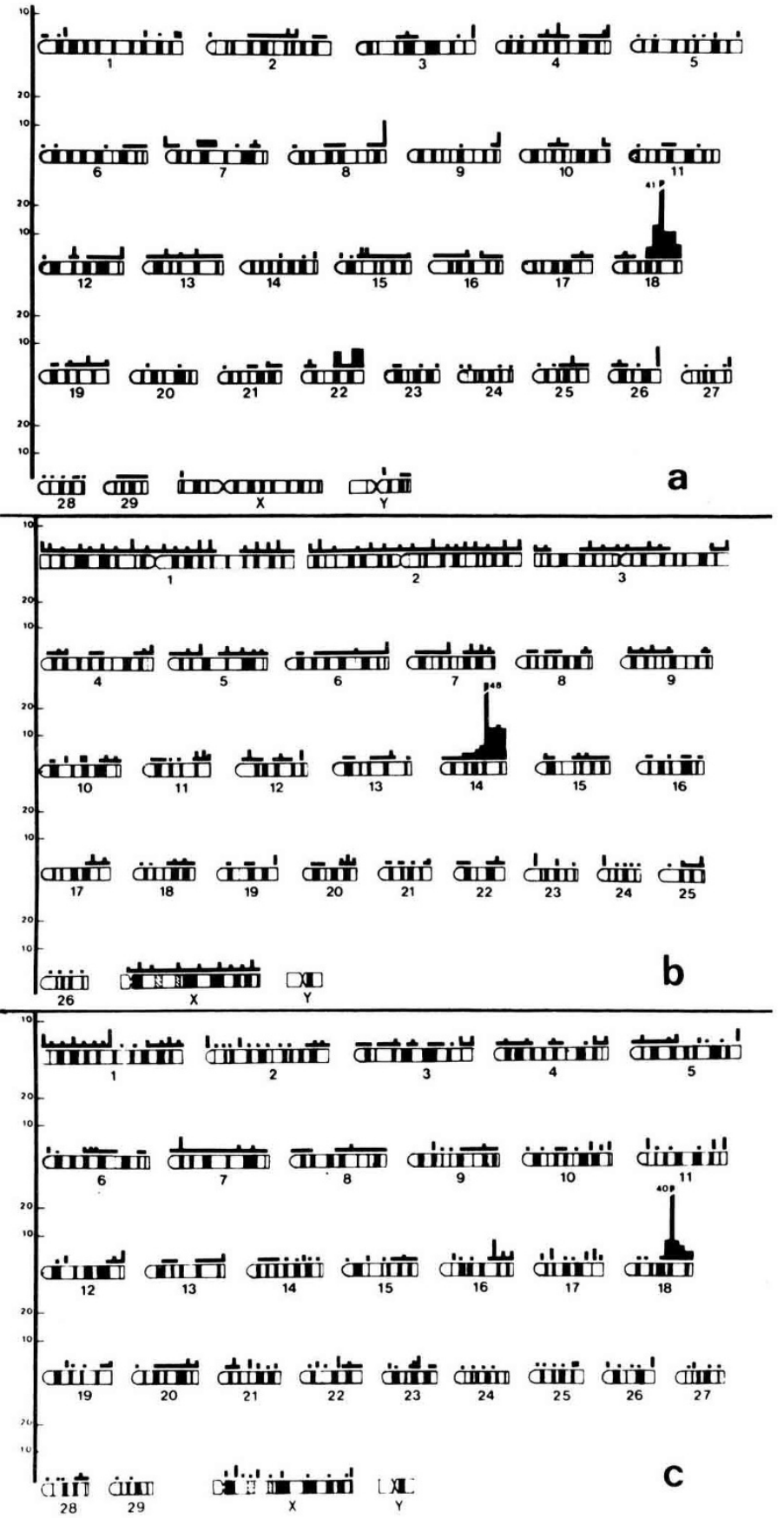

Fig 1. Grain distribution after in situ hybridization of the GPI8R DNA to (a) cattle, (b) sheep and (c) goat metaphase chromosomes. 


\section{Statistics}

In all three species, the $\mathrm{q} 22 \rightarrow$ proximal part of $\mathrm{q} 24$ constitutes less than $0.5 \%$ of the total genome. Statistical evaluation revealed that the probability of the presence of GPI8R DNA in this segment is highly significant $(P<0.01)$ in each species.

\section{DISCUSSION}

This study provides evidence that the glucose phosphate isomerase gene maps to chromosomes 18, 14 and 18 in cattle, sheep and goat, respectively. These three chromosomes have very similar banding patterns as well as hybridization signals using the GPI8R DNA probe. $87-94 \%$ of the grains on these chromosomes were located in the distal half with the peak on the same segment viz q22 $\rightarrow$ proximal part of q24, where approximately $62-73 \%$ of the total number of grains on these chromosomes were located. The chromosomal region q24 is a relatively large region. Comparatively few grains were observed in the middle and distal parts of this region. Thus the GPI gene has tentatively been assigned to the q22 $\rightarrow$ proximal part of q24 on chromosomes 18, 14 and 18 in cattle, sheep and goat, respectively, indicating the presence of similar genetic material in these regions which also appears to be similar after banding.

\section{REFERENCES}

Dutrillaux B, Couturier J, Evani V (1981) Chromosomal evolution in primates. Chromosomes Today $7,176-191$

Feinberg AP, Vogelstein B (1983) A technique for radiolabeling DNA restriction endonuclease fragments to high specific activity. Anal Biochem 132, 6-13

Graphodatsky AS (1989) Conserved and variable elements of mammalian chromosomes. In: Cytogenetics of Animals. (Halnan CRE, ed) CAB International, Oxon, UK, 95-123

Hediger R (1988) Die in situ-Hybridisierung zur Genkartierung beim Rind und Schaf. PhD Thesis. Eidgenössischen Technischen Hochschule, Zürich

ISCNDA (1989) International System for Cytogenetic Nomenclature of Domestic Animals. (Di Berardino D, Hayes H, Fries R, Long S, eds). Cytogenet Cell Genet 53, 65-79

Lalley PA, Davisson MT, Graves JAM, O'Brien SJ, Womack JE, Roderick TH, CreauGoldberg N, Hillyard AL, Dolittle DP, Rogers JA (1989) Report of the committee on comparative mapping. Human Gene Mapping 10. Cytogenet Cell Genet 51, 503-532

Levan G, Szpirer J, Szpirer C (1987) The rat gene map. Cytogenet Cell Genet 46, 649

Lin CC, Draper PN, DeBraekeleer M (1985) High-resolution chromosomal localization of the $\beta$-gene of the human $\beta$-globin gene complex by in situ hybridization. Cytogenet Cell Genet 39, 2269-2274

Mahdy EA, Mäkinen A, Chowdhary BP, Andersson L, Gustavsson I (1989) Chromosomal localization of the ovine major histocompatibility complex (OLA) by in situ hybridization. Hereditas 111, 57-90

Mäkinen A, Chowdhary BP, Mahdy E, Andersson L, Gustavsson I (1989) Localization of the equine major histocompatibility complex (ELA) to chromosome 20 by in situ hybridization. Hereditas 110, 93-96

O'Brien SJ, Seuanez HN, Womack JE (1985) On the evolution of genome organization in mammals. In: Molecular Evolutionary Genetics (MacIntyre RJ, ed). Plenum Publishing Corp, New York 
Popescu NC, Amsbaugh SC, Swan DC, DiPaolo JA (1985) Induction of chromosome banding by trypsin/EDTA for gene mapping by in situ hybridization. Cytogenet Cell Genet 39, 73-74

Sawyer JR, Hozier JC (1986) High resolution of mouse chromosomes: banding conservation between man and mouse. Science 232, 1632-1635

Yoshida MC (1984) Assignment of GDH and FUCA to rat chromosome 5: evidence for homologous linkage groups in rat, mouse and man. Cytogenet Cell Genet 37, 613 